\title{
LA LIBERTAD DE ESCOGER DESDE LAS REDES SOCIALES: REFLEXIONES DESDE LA REALIDAD PARAGUAYA
}

\author{
FREEDOM TO CHOOSE FROM SOCIAL NETWORKS: REFLECTIONS FROM THE \\ REALITY OF PARAGUAY
}

\author{
Noelia Bernadett Ozuna González* \\ Cecilio Arnaldo Rivas Ayala**
}

\begin{abstract}
Resumen:
El presente trabajo visa realizar un breve relato de la evolución de la manifestación del consentimiento del individuo para la formación y transformación de la sociedad civil a través de los medios tecnológicos disponibles. Para ello, se toma por base la teoría de la formación de la sociedad civil defendida por John Locke y a partir de ella se describe, en la sociedad moderna, los medios que permiten que la misma siga transformándose por la voluntad ciudadana, la que encontrando afines y que mediante la formación de redes lograr ingresar a la agenda pública. Del mismo modo se presentan reflexiones, acerca de la realidad paraguaya en el contexto del uso de internet, otorgando énfasis a la utilización de las redes sociales como herramienta de los usuarios para la convocación de manifestaciones.
\end{abstract}

Palabras Clave: Internet, Redes sociales, Comunicación virtual, Paraguay.

\begin{abstract}
:
This work aims to make a brief account of the evolution of the manifestation of individual consent for the formation and transformation of civil society through technological means. To do this, it takes as a basis the theory of the formation of civil society advocated by John Locke and from it, this paper describes, in modern society, the means allowing civil society to continue transforming itself by the citizen will, that finding related people and through networking gain entry to the public agenda. Similarly reflections about the Paraguayan reality in the context of Internet use are presented, giving emphasis to the use of social networks as a tool for users for convening protests.
\end{abstract}

Keywords: Internet, social networks, virtual communication, Paraguay.

\section{Introducción}

La libertad no es una página blanca sobre la que se proyectan nuestros sueños.

\footnotetext{
* Maestranda en Ciencias Sociales de la Universidad Nacional del Este. Integrante del Grupo Núcleo de Investigación, Escuela de Posgrado de la Universidad Nacional del Este. Coordinación del Dr. Prof. Aníbal Orué Pozzo. Ciudad del Este, Alto Paraná - Paraguay. Correo: berna_dett@hotmail.es

** Docente Investigador - Coordinador del Centro de Investigaciones en Derecho y Ciencias Sociales de la Universidad Privada del Este (UPE), Sede Central Ciudad Presidente Franco (Paraguay). Magíster en Derecho Ambiental por la Universidad Católica "Nuestra Señora de la Asunción" (Asunción - Paraguay). Magíster en Derecho Ambiental por la Université de Limoges (Limoges - Francia). Abogado y Notario. Correo electrónico: arrnaldo_1982@ @otmail.com
} 
Es el tejido áspero en el que se manifiestan los poderes que estructuran la sociedad. (Castells, 2001).

El presente trabajo es un intento de reflexión sobre los hechos que han motivado las manifestaciones en Asunción y el interior en los meses de mayo y junio del 2012 y cuyos principales actores, se sostiene, han surgido de redes sociales.

A los efectos de enmarcar teóricamente tales hechos, en la primera parte se busca enlazar las ideas sobre la libertad individual del teórico inglés Jonh Locke, la cual desde su concepción, da origen a la sociedad civil. Este concepto es importante, principalmente en el momento actual que ve el surgimiento del concepto de Sociedad de la Información, y puede contribuir en la clarificación de algunos aspectos relacionados a la emergencia de esta sociedad, asimismo en el uso que determinados sectores hacen de las redes sociales.

Para explicar la transformación de estas redes sociales desde la aparición de Internet se toman los estudios de sociólogo español Manuel Castells y se explican algunos conceptos por él desarrollados como virtualidad real y sociedad red.

En una segunda parte se plantea introducir la discusión en el ámbito de la sociedad paraguaya y verificar si el uso de las tecnologías de la información y la comunicación (TICs) en sentido amplio han contribuido a determinar una mayor participación del ciudadano paraguayo en los temas políticos de mayor repercusión, en especial, de los sucesos ocurridos en los meses de mayo y junio del año 2012.

Para ello se parte de un análisis inicial de datos estadísticos sobre la penetración.

Se escoge a Jonh Locke en virtud de la valorización de la voluntad del Individuo en especial; lo cual se sugiere como aspecto resaltante en la evolución del uso de las TICs. No el buen salvaje que cuando está en comunidad es todo para la comunidad de Rousseau, ni el Homo homini lupus de Hobbes, para quien el individuo solo se civiliza en el Estado que resulta ser un monstruo.

1 El concepto de libertad en la visión de John Locke y el origen de la sociedad civil 
¿Qué es la Libertad?

Hacer esta pregunta implica rever la condición de ser humano. ¿Es el mismo libre? ¿Cómo sabe que es libre?

El tema de la libertad es ampliamente analizado por John Locke en sus dos tratados o ensayos (según sea la traducción adoptada) sobe el gobierno civil:

Las ideas políticas de Locke salen a luz en sus dos tratados sobre el gobierno civil. En particular, en el "Segundo tratado sobre el gobierno civil" donde aporta uno de los textos más influentes en la historia del pensamiento político. El primer "Tratado" es una crítica al absolutismo político y a la idea de una monarquía de origen divino; el segundo se refiere al origen y a los objetivos del gobierno civil. (Bernardino Cano Radil, Tomo I, 2009, p. 289)

Y no solo del gobierno civil, pero del Estado en sí, llamado por Locke como "sociedad civil", "sociedad política", "cuerpo político", "comunidad política" (commonwealth), simplemente comunidad "community" o "pueblo". Y en la génesis de esta sociedad está la libertad, primero natural, luego civil.

Locke distingue en el individuo un estado de "perfecta libertad", aquella para "para ordenar sus acciones, y disponer de sus personas y bienes como lo tuvieren a bien, dentro de los límites de la ley natural, sin pedir permiso o depender de la voluntad de otro hombre alguno" (John Locke, s.f. p. 3)

Llama genéricamente bienes o propiedad a la vida, libertad y posesiones. El individuo perfectamente libre se halla en estado natural, o estado de naturaleza como lo llama Locke. En tal estado el individuo es regido por la ley natural que descubre por el recto uso de la razón y que sirve de valla al ejercicio de la libertad.

Así como explica W.R. Daros (2009, p. 8)

La libertad inicialmente consiste en un poder determinarnos a actuar por el propio juicio. Ella es el origen de todos nuestros derechos naturales. El fin de nuestra libertad es poder alcanzar el bien que elegimos: esto hace a la esencia de la persona, de la naturaleza humana y del derecho. Es propio de la persona humana buscar la verdad y elegir lo que considere mejor: ninguna de ambas cosas se puede hacer sin libertad. 
Y el individuo no es solo naturalmente libre, sino, además, naturalmente igual. Al estar sometido nada más que a los dictados de la ley natural y no reconocer sobre sí otro soberano más que sí mismo, el individuo se halla en igualdad de condiciones con otros individuos.

Estado también de igualdad, en que todo poder y jurisdicción es recíproco, sin que al uno competa más que al otro, no habiendo nada más evidente que el hecho de que criaturas de la misma especie y rango, revueltamente nacidas a todas e idénticas ventajas de la Naturaleza, y al liso de las mismas facultades, deberían asimismo ser iguales cada una entre todas las demás, sin subordinación o sujeción, a menos que el señor y dueño de ellos todos estableciere, por cualquier manifiesta declaración de su voluntad, al uno sobre el otro, y le confiriere, por nombramiento claro y evidente, derecho indudable al dominio y soberanía. (John Locke, s.f. p. 3)

Explica Óscar Godoy Arcaya (2004, p. 161) que:

La libertad de los individuos en estado de naturaleza, o estado moral original del hombre, consiste en que nacen dotados de la facultad de juzgar y decidir por sí mismos acerca de lo que es necesario y suficiente para su conservación y bienestar, sin estar sujetos a la autoridad de ningún otro hombre, salvo la de Dios. Esta capacidad, igualmente repartida entre todos los miembros del género humano, los hace independientes, o sea, dependientes sólo de sí mismos, exentos de toda sujeción o dominación terrenal.

Ahora bien, aunque todos los individuos nacen dotados de razón para descubrir las leyes de la naturaleza, no todos lo hacen, o hacen recto uso de la libertad de que la que gozan. De esta forma Locke explica que el "estado de libertad no lo es de licencia" (s.f. p. 3). Por ello, "no es libre de destruirse a sí mismo, ni siquiera a criatura alguna en su poder, a menos que lo reclamare algún uso más noble que el de la mera preservación” (s.f. p. 3)

Cuando el individuo arremete contra la libertad de otro individuo, contra los dictados de la ley natural se coloca en estado de guerra.

El estado de guerra lo es de enemistad y destrucción; y por ello la declaración por palabra o acto de un designio no airado y precipitado, sino asentado y decidido, contra la vida de otro hombre, le pone en estado de guerra con aquel a quien tal intención declara, y así expone su vida al poder de tal, pudiéndosela quitar éste, o cualquiera que a él se uniere para su defensa o hiciere suya la pendencia de él (...) (J. Locke, s.f. p. 7)

Al contrario de la concepción hobbesiana en donde el hombre es lobo para el hombre, para Locke, el estado de conflicto no es natural en el hombre:

(...) el estado de naturaleza es -hipotéticamente- placentero y pacífico. No es necesariamente una guerra de todos contra todos, es un estado pre-político pero no pre-social, y el hombre vive guiado por la ley natural a través de su razón. Esto 
implica que los hombres podrían vivir vidas ordenadas y morales antes de establecer la sociedad política. Además, podrían disfrutar de su propiedad siempre y cuando dejaran lo suficiente para satisfacer las necesidades de los otros. (Tomás Várnagy, s.f. p. 58)

Como "en el estado de naturaleza todos son reyes" y "la mayor parte de ellos no observa estrictamente la equidad y la justicia, el disfrute de la propiedad que un hombre tiene en un estado así es sumamente inseguro" (Cano Radil, Tomo I, 2009, p. 293)

Es así que para garantizar el goce de esos bienes cierto número de individuos renuncia a su poder de ejecución de la ley natural y la coloca en manos de un juez que resuelva en los conflictos. Y esa renuncia se hace mediante un pacto o contrato: “(...) siempre que cualquier número de hombres de tal suerte en sociedad se junten y abandone cada cual su poder ejecutivo de la ley de naturaleza, y lo dimita en manos del poder público, entonces existirá una sociedad civil o política.” (J. Locke, s.f. p. 21)

En este punto surgen dos conceptos importantes, que serán claves para comprender el papel que cumplirán los modernos medios de comunicación tan presente en la vida de las personas en el siglo XXI: voluntad y consentimiento.

Explica Locke que "Cuando cualquier número de gentes hubieren consentido en concertar una comunidad o gobierno, se hallarán por ello asociados y formarán un cuerpo político, en que la mayoría tendrá el derecho de obrar y de imponerse al resto.” (s.f. p. 24) Más abajo explica que el consentimiento es dado por cada individuo (s.f. p. 24). Siendo así, el nacimiento de la sociedad política es un acto de voluntad individual aunado a otras voluntades individuales similares las cuales permiten que la voluntad de la mayoría sea, desde ese momento, la que determine los derroteros de la entidad surgida mediante leyes civiles que visen la garantía de los bienes individuales, que al fin de cuentas, es la finalidad de esta sociedad civil: "El fin, pues, mayor y principal de los hombres que se unen en comunidades políticas y se ponen bajo el gobierno de ellas, es la preservación de su propiedad; para cuyo objeto faltan en el estado de naturaleza diversos requisitos". (J. Locke, s.f. p. 32)

Entre los requisitos que faltan menciona: primero "una ley conocida, fija, promulgada, recibida y autorizada por común consentimiento como patrón de bien y mal, y medida común para resolver cualesquiera controversias que entre ellos se produjeren" (J. 
Locke, s.f. p. 32); y segundo: "un juez conocido e imparcial, con autoridad para determinar todas las diferencias según la ley establecida" (J. Locke, s.f. p. 32)

Ahora bien, ¿qué sucede con los que no expresan esa voluntad de conformar una sociedad civil?, ¿quedan al margen de la sociedad, relegados, olvidados, sustraídos al poder civil?

Explica Locke la distinción entre consentimiento expreso y tácito para determinar los alcances del poder civil sobre los miembros y no miembros de la comunidad política. Dice:

Nadie duda que el consentimiento expreso de un hombre cualquiera al entrar en cualquier sociedad, le hace miembro perfecto de ella y súbdito de aquel gobierno. La dificultad consiste en lo que deba ser tomado por consentimiento tácito, y hasta qué punto obligue: esto es, hasta qué punto deba considerarse que uno consintiera, y por tanto se sometiera a un gobierno dado cuando no hizo expresión alguna de su determinación. Y aquí diré que todo hombre en posesión o goce de alguna parte de los dominios de un gobierno dado, otorga por ello consentimiento tácito, y en igual medida obligado se halla en la obediencia de las leyes de aquel gobierno, durante tal goce, como cualquier otro vasallo, bien fuere, tal posesión de hacienda, suya y de sus herederos a perpetuidad, o mero albergue para una semana, o aunque se limitare a viajar libremente por carretera; y, en efecto, se extiende tanto como la propia presencia de cada uno en los territorios de aquel gobierno. (J. Locke, s.f. p. 30/31)

Explica W.R. Daros (2009, p. 15):

Siendo las opiniones de los hombres tan diversas, no se puede esperar que la sociedad civil o Estado se forme con el consentimiento explícito de todos los ciudadanos. Es suficiente que la mayoría de los habitantes esté de acuerdo en constituirla y exprese su consentimiento a un pacto, en forma tácita, por "el hecho de nacer y vivir dentro del territorio de dicho gobierno". Quien no se halla conforme con las leyes de un Estado, puede vender sus tierras y queda libre de marcharse, incorporándose a otro Estado o formar otro en tierras libres.

Así, la libertad natural del individuo es reemplazada por la libertad civil:

“(...) la sujeción voluntaria (...) es positivamente libertad civil. (...) la libertad natural se hace a sí misma libertad civil a través de contrato. (...) una libertad que consiste en no estar sometido a otro poder legislativo que aquel establecido por el consentimiento de la comunidad política (...)”(O. Godoy Arcaya, 2004, p. 165/166)

Señala Locke que una vez constituida la sociedad política y que el hombre haya dejado el estado de naturaleza ya no es posible volver a ella, salvo que se por vía de la conquista de un estado extranjero por otro. 
El individuo al adquirir la libertad, queda sometido a los dictados de las leyes emanadas del poder legislativo para el gobierno de la sociedad civil, pero a la vez el individuo conserva una gama amplia de derechos que se refieren a su autogobierno y que son anteriores al nacimiento de esa sociedad civil. Son los que Locke llama "libertad para inocentes deleites" (Locke, s.f. p. 128), que hacen referencia a "elegir todo aquello relacionado con el goce de de las cosas agradables de la vida y que forman parte del bienestar del hombre.”. Otra facultad que permanece en poder del pueblo es la facultad de legislar, que solo a título de fideicomiso es entregado a la asamblea o poder legislativo; del cual puede ser retirado de no observar la voluntad popular. Y habida cuenta que el pueblo conforma la voluntad de cada individuo de constituirse en cuerpo político, podemos decir que, también cada individuo conserva la facultad originaria de auto legislación. Sin embargo ese retiro no se hace de forma arbitraria, sino que está a su vez delimitada por la observancia de ciertos requisitos, tales como "la evaluación de la performance de aquel o aquellos en los cuales se delegó el ejercicio del poder legislativo" (O. Godoy, Arcaya, 2004, p. 176)

\title{
2 Los orígenes de Internet: ¿Sociedad del Conocimiento o Sociedad de la Información?
}

Describe Manuel Castells lo que llama la revolución de la tecnología de la Información del Siglo XX. Sostiene:

\begin{abstract}
Aunque pueden encontrarse precedentes científicos e industriales de las tecnologías de la información basadas en la electrónica unas décadas antes de 1940 (no siendo la menos importante la invención del teléfono por Bell en 1876, de la radio por Marconi en 1898 y el tubo de vacío por De Forest en 1906), fue durante la Segunda Guerra Mundial y el periodo subsiguiente cuando tuvieron lugar los principales avances tecnológicos en la electrónica: el primer ordenador programable; y el transistor, fuente de la microelectrónica, el verdadero núcleo de la Revolución de la tecnología de la información en el siglo XX. No obstante, hasta la década de los setenta no se difundieron ampliamente las tecnologías de la información, acelerando su desarrollo sinergético y convergiendo en un nuevo paradigma. (Castells, 1997, p. 67)
\end{abstract}

Señala fechas claves en la evolución tecnológica que permitieron la aparición y difusión de lo que se conoce como Internet:

- 1946: se produce el primer ordenador con fines generales, el ENIAC (Electronic Numerical Integrator and Calculator), que pesaba 30 toneladas y ocupaba la superficie de un gimnasio.

- 1957: Se inventa el circuito integrado, más conocido como chip. 
- 1971: se inventa el microprocesador, que empieza a difundirse a mediados de los `70 y permite colocar un ordenador en un chip.

- 1975: se inventa la Altair, una caja de cálculo diseñada como un ordenador de pequeña escala en torno a un microprocesador. Nacía el microordenador.

- 1977: se lanza la Apple II, el primer microordenador que gozó de éxito comercial.

- 1977: la Microsoft comienza a producir sistemas operativos para los microordenadores.

El costo ínfimo del chip, su gran capacidad de memoria y la posibilidad de producción en gran escala determinó una revolución en la tecnología. Hizo surgir toda suerte de aparatos electrónicos, entre ellos, quizá el más importante es la PC, o la computadora personal. La utilidad de este aparato no estaba en tela de juicio. Siendo universitarios y académicos los primeros a diseñarlo, pronto reconocieron su utilidad para procesar gran cantidad de información. No se tardó en ponerlos en red.

Continúa relatando Castells que "desde mediado de la década de 1980, los microordenadores no pueden concebirse en aislamiento: actúan en redes con una movilidad creciente, mediante ordenadores portátiles". (Castells, 1997, p. 71)

Auspiciado por la Advanced Research Project Agency (Agencia de Proyectos de Investigación Avanzada) - ARPA - del Departamento de Defensa estadounidense se estableció una red de comunicaciones para facilitar el flujo de información entre las unidades académicas y científicas colaboradoras del mismo. Eso fue en el año de 1969, surgía al ARPANET. Señala Castells:

(...) los científicos comenzaron a utilizarla para toda clase de propósitos comunicativos. En un momento dado se hizo difícil separar la investigación de orientación militar de la comunicación científica y las charlas personales... se concedió acceso a la red a los científicos de todas las disciplinas y, en 1983, hubo una división entre ARPANET, dedicada a propósitos científicos, y MILNET, directamente orientada a las aplicaciones militares. (Castells, 1996, p. 385)

Si bien surgieron otras redes científicas, todas usaban ARPANET como sistema de comunicación. "La red de redes que formaron durante los años ochenta se llamó ARPA INTERNET, luego INTERNET, respaldada aun por el Departamento de Defensa, y manejada por la National Science Foundation.” (Castells, 1996, p. 385) 
A la gran popularidad de Internet contribuyó también "la cultura de movimientos libertarios, contestatarios, que buscaban en ello un instrumento de liberación y de autonomías respecto al Estado y a las grandes empresas" (Castells, 2002, p. 2)

Por ser Internet una tecnología del tipo abierta y de libre uso los llamados hackers, con su pasión por "inventar programas y desarrollar nuevas formas de procesamiento de información y comunicación electrónica" (Castells, 2001), y mediante la colaboración abierta y sin anhelar más beneficio que el reconocimiento de sus pares, han generado, aplicación tras aplicación, una suerte de bola de nieve electro-informática. Hoy en día se estima que Internet es utilizada por $32,78 \%$ de la población mundial, conforme dato del Banco Mundial hasta el año de 2011. (Banco Mundial, 2013)

Se puede considerar que la transformación de Internet es, por tanto, un proceso multidimensional que implica el actuar sinérgico de varios actores, que por su vez, permitió una mayor acumulación información, debido al dinamismo en la generación e intercambio de datos.

Pero, ¿esta gran cantidad de información implica mayor conocimiento? Generar información y producir conocimiento son procesos que han determinado el debato sobre cómo describir el momento histórico actual.

Para algunos estamos delante de la Sociedad de la Información, término que surge con Daniel Bell en 1973, pero cobra fuerza en los '90 con el desarrollo de Internet y las tecnologías de la Información y la Comunicación (TIC). Su uso es auspiciado por varios órganos mundiales, como la Unión Internacional de Telecomunicaciones - UIT -, la Organización Mundial del Comercio - OMC - y el Banco Mundial; así como fue adoptado para pautar las reuniones sobre dicha materia del G8 y Estados Unidos.

En general, utilizar la citada denominación es a los efectos de hacer referencia al uso intensivo de las tecnologías de la información y la comunicación (TICs), cuya abanderada actual es Internet, pero que también implica el uso de la telefonía ya sea fija o celular, nacional o internacional, TV sea por digital, por cable o por satélite, y toda la gama de aparatos electo-electrónicos que facilitan la comunicación y la interacción. 
En el año de 2003 se celebró en Ginebra la 1ra. Cumbre Mundial de la Sociedad de la Información, con los auspicios de la UIT y las Naciones Unidas. Una segunda etapa de esta Cumbre se llevó a cabo dos años más tarde (2005) en Túnez. El principal objetivo de estas conferencias fue diseñar planes de acción que permitieran disminuir los que llamaron la "brecha digital", esto es:

(...) la separación que existe entre las personas (comunidades, estados, países...) que utilizan las Tecnologías de Información y Comunicación (TIC) como una parte rutinaria de su vida diaria y aquellas que no tienen acceso a las mismas y que aunque las tengan no saben cómo utilizarlas. (Serrano Santoyo y Martínez Martínez, 2003, p. 8)

Por su lado, la denominación "sociedades del conocimiento" es más utilizada en los ámbitos académicos y se presenta más bien como un modelo evolucionado de la sociedad de la información. En efecto, como se explica en el Informe Mundial de la UNESCO, "Hacia las sociedades del conocimiento" (2005), "la noción de sociedad de la información se basa en los progresos tecnológicos. En cambio, el concepto de sociedades del conocimiento comprende dimensiones sociales, éticas y políticas mucho más vastas” (p. 17)

\begin{abstract}
El nacimiento de una sociedad mundial de la información como consecuencia de la revolución de las nuevas tecnologías no debe hacernos perder de vista que se trata sólo de un instrumento para la realización de auténticas sociedades del conocimiento (...)

La información es efectivamente un instrumento del conocimiento, pero no es el conocimiento en sí. La información, que nace del deseo de intercambiar los conocimientos y hacer más eficaz su transmisión, es una forma fija y estabilizada de éstos que depende del tiempo y de su usuario: una noticia es "fresca" o no lo es. La información es en potencia una mercancía que se compra y vende en un mercado y cuya economía se basa en la rareza, mientras que un conocimiento -pese a determinadas limitaciones: secreto de Estado y formas tradicionales de conocimientos esotéricos, por ejemplo- pertenece legítimamente a cualquier mente razonable, sin que ello contradiga la necesidad de proteger la propiedad intelectual. La excesiva importancia concedida a las informaciones con respecto a los conocimientos pone de manifiesto hasta qué punto nuestra relación con el saber se ha visto considerablemente modificada por la difusión de los modelos de economía del conocimiento. (UNESCO, 2005, p. 19)
\end{abstract}

Así, desde esta perspectiva, para llegar a las sociedades del conocimiento se debe superar el simple recibir y emitir información y empezar a discernir lo que esa información significa.

En las sociedades del conocimiento todos tendremos que aprender a desenvolvernos con soltura en medio de la avalancha aplastante de informaciones, y también a desarrollar el espíritu crítico y las capacidades cognitivas suficientes para diferenciar la información "útil” de la que no lo es. (UNESCO, 2005, p. 20) 
El uso de la denominación "sociedad del conocimiento" o "sociedades del conocimiento", según la acepción de la UNESCO, se hizo popular desde la década de los '90 y tal como resulta de lo expresado más arriba es patrocinado mayormente por la UNESCO.

No obstante la disputa ser más frecuente estas las denominaciones apuntadas, otras más fueron acuñadas en el intento de describir la los tiempos actuales. Así tenemos el concepto de sociedad red defendido por Manuel Castells en una trilogía que describe la revolución de la información en el siglo XX: La era de la Información, Economía, Sociedad y Cultura: Tomo I, La Sociedad Red; Tomo II, El poder de la Identidad y Tomo III, El fin del Milenio.

\section{El concepto de red en la Sociología}

Define Manuel Castells la red del siguiente modo: "Una red es un conjunto de nodos interconectados. Los nodos pueden tener mayor o menor relevancia para el conjunto de la red, de forma que los especialmente importantes se denominan «centros» en algunas versiones de la teoría de redes." (Manuel Castells, 2009, p. 45)

Los nodos son los puntos donde se unen las diferentes ramas de la red. Así se tiene el siguiente ejemplo gráfico, conforme a lo detallado por David Ugarte en la obra " $E l$ poder de la redes" (s.f.):

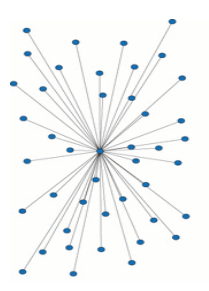

Red Centralizada

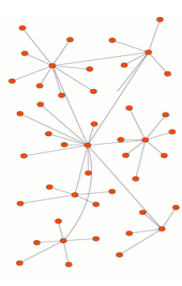

Red Descentralizada

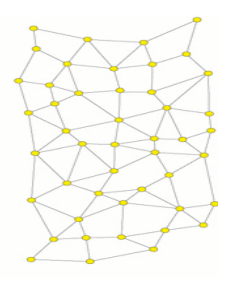

Red Distribuida

Los gráficos enseñan los distintos tipos de redes que pueden ser existir y su estructura. En efecto, la llamada teoría de las redes tiene un fundamento de las teorías estructuralistas de la sociedad acompañadas de elementos traídos de la matemática y de la informática. Al respecto explica Gina Gertrudis Cardozo Cabas, (2009, p. 1) cuanto sigue: 
antropología; la sicología con la teoría de sociogramas, y la matemática con la teoría de grafos este último muy necesario para la formalización del concepto.

No obstante la explicación presentada por la citada autora, la misma también aclara más adelante que no existe una teoría de las redes propiamente, sino más bien formas de estudiar a las redes:

El análisis sociológico a partir del concepto de redes aún no constituye una teoría formal o unitaria en el sentido de especificar leyes distintas, proposiciones, o correlaciones. En lugar de esto, lo que existe es una estrategia amplia para la investigación de la estructura social (Scott, 2000; Wasserman y Faust, 1994; Emirbayer y Goodwin, 1994), apoyándose en el análisis de procesos históricos y en los métodos tradicionales de la etnografía, antropología, de los estudios de caso y de la sociología histórica. Castells (2000) y Graham y Marvin (1996) han evaluado el impacto de la estructura en redes en la reorganización de la sociedad, según los principios de la sociedad de la información; Villasante (2002) y Scherer-Warren (2005), utilizan la perspectiva de redes para entender los movimientos sociales, que unen a individuos y actores colectivos a través de lazos de solidaridad que transcienden a organizaciones empíricamente delimitadas. (Gina Gertrudis Cardozo Cabas, 2009, p. 5)

Volviendo a los gráficos presentados se tienen las siguientes tipologías de redes, conforme lo esbozado por Cardozo Cabas (2009, p. 22): a) la centralizada, donde los nodos se conectan a través de un único nodo que concentra y distribuye la información. Estos nodos no se conocen entre sí, sino a través del nodo central, y si éste desaparece la red se pierde; b) la descentralizada, que multiplica la estructura anterior en varias redes centralizadas. Sin embargo, se diferencia de la red centralizada en que la información no se concentra en un solo actor, sino en varios, por lo que en caso de desconexión, no toda la información es frenada o perdida. Mas, aun presenta el problema de que cuando cae un nodo, los demás que se conectan por medio de él a la red quedan incomunicados de ella; y c) la distribuida, donde cualquier nodo se conecta con cualquier otro, diseminando la información de forma más eficiente y logrando que la desaparición de un nodo no afecte de forma irrevocable la estructura de la red. Esta opción que plantea una topología descentralizada es la que describe mejor las topologías de las redes en internet, en particular las redes sociales.

En lo que respecta a la importancia o no un nodo específico para la red explica Castell (2009, p. 45) la misma "no proviene de sus características especiales, sino de su capacidad para contribuir con de la red para lograr sus objetivos", cuanto más información absorban y la procesen eficientemente, aumenta su importancia. Pero aclara que "todos los nodos de la red son necesarios para el funcionamiento de la propia red, aunque las redes permiten cierta redundancia como salvaguarda para su propio funcionamiento", lo que implica que pueden haber nodos realizando las misma tareas de otros nodos, pero a los efectos 
de la salvaguarda y distribución más rápida de la información tal repetición de funciones es no resulta prejudicial. En caso de que un nodo deje de funcionar, el que realiza similares funciones continúa con la tarea que dejó de hacer el desaparecido. Por otro lado las redes "tienden a reconfigurarse", eliminando algunos nodos y añadiendo otros nuevos. Así, "los nodos existen y funcionan exclusivamente como componentes de las redes. La red es la unidad, no el nodo." (2009, p. 45)

Para Castells se vive un nuevo paradigma propiciado por la "aplicación de (...) conocimiento e información a aparatos de generación de conocimiento y procesamiento de la información/comunicación, en un círculo de retroalimentación acumulativo entre la innovación y sus usos" (1996, p. 58)

Este paradigma de la Tecnología de la Información se materializa en lo que denomina la Sociedad Red, que la define del siguiente modo:

(...) es una estructura social basada en redes operadas por tecnologías de comunicación e información fundamentadas en la microelectrónica y en redes digitales de computadoras que generan, procesan y distribuyen información a partir del conocimiento acumulado entre los nodos de esas redes. (Manuel Castells y Gustavo Cardoso, 2005, p. 20)

Este nuevo paradigma tiene por características según Castells (1996, p. 88/89):

1) La información constituye su materia prima. La tecnología generada a partir de la información actúa sobre la información en un círculo acumulativo y retroalimentado y no solo, como en las anteriores revoluciones como la Industrial, donde la información actuaba sobre la tecnología.

2) Las nuevas tecnologías presentan gran capacidad de penetración al punto que “todos los procesos de nuestra existencia individual y colectiva están directamente moldeados (aunque sin duda no determinados) por el nuevo medio tecnológico" (Castells, 1996, p. 88)

3) Estas nuevas tecnologías de la comunicación generan un conjunto de relaciones que se manifiestan en la forma de redes, mediante la lógica de la interconexión. Tales relaciones surgen de la interacción creciente y su desarrollo es de efectos impredecibles.

4) La flexibilidad en la interacción es la cuarta característica. Los procesos son reversibles, las organizaciones e instituciones pueden modificarse y los componentes pueden ser reordenados. Sin embargo, Castells es cuidadoso para afirmar las consecuencias de querer extrapolar esta flexibilidad a la sociedad y a las personas: “sólo los análisis específicos y la observación empírica serán capaces de determinar 
el resultado de la interacción de las nuevas tecnologías y las formas sociales emergentes." (Castells, 1996, p. 89)

5) La última característica es la "convergencia creciente de tecnologías especificas en un sistema altamente integrado" (Castells, 1996, p. 89). Todos los aparatos electro-electrónicos inventados para la comunicación y generación de información están conectados y tienen a Internet por enlace. Incluso los que aun no tienen existencia material ya son calculados para que se integren a esta conexión. Toda forma de telecomunicación está aunada para procesar información, y se unen a la red que a su vez es operada por ordenadores.

\section{Las redes sociales}

Conforme se ha explicado más arriba, las redes son herramientas útiles de intercambio de información. Son básicamente estructuras creadas para la comunicación. Su aparición no es un fenómeno moderno, mucho menos se circunscribe al ámbito informático. Sin embargo, fue el enorme avance experimentado en esa área que hizo con que el fenómeno de las redes sociales trascendiera los espacios geográficos primarios en que pudieran haber surgido inicialmente.

Sobre el tema resulta interesante el trabajo de Ilse Scherer-Warren, "Redes sociales y de movimientos en la sociedad de la información” (2005) en donde la misma describe desde una perspectiva multidimensional el fenómeno de las redes sociales.

Es así como menciona que "las redes sociales surgen en la década de los '40 para ocuparse de la comprensión de las relaciones inter-personales en contextos comunitarios circunscritos." (Ilse Scherer-Warren, 2005, p. 77/78). No obstante, para la sociología su estudio tuvo mayor interés con la repercusión del "análisis de acciones colectivas más amplias y de movimientos sociales" desarrollada desde los años 70. (Scherer-Warren, 2005, p. 78)

Las acciones colectivas y los movimientos sociales solo son posibles mediante las acciones en red, por el flujo de informaciones que son capaces de procesar:

(...) las redes son complejas estructuras de comunicación establecidas en torno a un conjunto de objetivos que garantizan, al mismo tiempo, unidad de propósitos y flexibilidad en su ejecución gracias a su capacidad para adaptarse al entorno operativo. Las redes están programadas y al mismo tiempo son auto configurables. 
En las redes sociales y organizativas, los objetivos y procedimientos operativos son programados por los actores sociales. Su estructura evoluciona de acuerdo con la capacidad de la red para autoconfigurarse en una búsqueda interminable de disposiciones de red más eficientes. (Manuel Castell, 2009, p. 46)

Scherer-Warren (2005, p. 83) menciona redes primarias, las cuales son presenciales, las que crean territorios continuos geográficamente delimitados; y las redes virtuales las cuales intencionales y "trascienden las fronteras espaciales de las redes virtuales"

En cuanto a las relaciones dentro de las redes menciona a aquellas con vínculos personalizados que son más directos "establecidos entre actores en sus cotidianos, en el ámbito de sus comunidades, en el espacio más restringido de las organizaciones colectivas específicas", tales como la familia, el vecindario, el lugar de trabajo. Por el otro lado están los que se constituyen en virtud de afinidades políticas, "entre actores y organizaciones, en espacios definidos por la conflictividad de la acción colectiva, pudiendo (...) trascender los espacios de emergencia de la acción, (...) se construyen en torno de identidades de carácter ideológico o de identificaciones políticas o culturales." (Scherer-Warren, 2005, p. 86) en este tipo de interacciones, las relaciones son mas horizontales, las "prácticas políticas poco formalizadas o institucionalizadas entre organizaciones de la sociedad civil, grupos identitarios y ciudadanos movilizados", los cuales por su vez son "comprometidos con conflictos o solidaridades, con proyectos políticos o culturales comunes, construidos sobre la base de identidades y valores colectivos" (Scherer-Warren, 2005, p. 86)

Sin embargo, las categorías de relaciones apuntadas no son taxativamente demarcadas. Redes presenciales pueden sufrir influencia de redes virtuales y lo mismo, éstas pueden tener su génesis en redes inicialmente virtuales. De esta forma se genera "una constante dialéctica entre lo local y lo más global, entre lo presencial y lo virtual, entre el activismo de lo cotidiano y el ciberactivismo, tratando de ayudar a la formación de movimientos ciudadanos planetarizados.” (Scherer-Warren, 2005, p. 86

La actividad en red permite que los puntos de vista afines se encuentren y canalicen sus esfuerzos para obtener mayor atención a los temas defendidos por los grupos o movimientos integrados en red.

Menciona David Ugarte en "El poder de las redes - Manual Ilustrado para cieberactivistas", (s.f.) que la primera actividad en rede fue promovida por los sindicatos y 
grupos obreros al hacer la convocatoria a la Primera Internacional, en el año de 1864, valiéndose del nuevo tendido de los telégrafos. Aquellos vieron en este medio la "posibilidad de coordinar sus reivindicaciones (...)" (David Ugarte, s.f.)

Luego, los movimientos por el reconocimiento de los derechos de la mujer, el fin de la segregación racial, el ecologismo y apertura a la democracia de los gobiernos latinoamericanos también se valió de la actividad en red para presentar reclamos, coordinar actos, intercambiar datos y fortalecerse. Ello haciendo uso de lo que la tecnología ponía a disposición: telégrafo, cartas, teléfono fijo, etc.

Pero la aparición de la informática, su popularización y la posterior conexión en red de los ordenadores dio contribuyó a que las acciones en redes sean más frecuentes, valiéndose de la facilitación de la comunicación que supone la tecnología.

Las redes sociales permiten la aproximación del pasado y del presente en el ciberespacio, lo que implica un mayor intercambio de cultura, conocimientos y la posibilidad de afianzamiento de los lazos o la creación de nuevos vínculos, por medio de las redes sociales virtuales.

Así, sostiene David Ugarte que en las llamadas "Revolución de Colores" de los países de Europa Oriental, en la región de ex repúblicas soviéticas, contra sus respectivos gobiernos autoritarios el elemento común para las determinar la agenda pública fue lo que llama "blogsfera". En la misma, por medio de blogs los ciudadanos indignados podían evadir el férreo control que el Estado ejercía sobre los medios de comunicación usuales y, así, expresar sus opiniones, auto convocarse a las manifestaciones y ejercer presión sobre los organismos internacionales de tal forma a intervenir en el país.

El ejemplo más reciente de este tipo de uso de las redes sociales, en especial por los medios electrónicos, es la llamada "Primavera Árabe" que con su inicio en Túnez en 2010, logró servir de ejemplo a ciudadanos de otros países y consiguió el derrocamiento de gobiernos con años de ejercicio autoritario del poder: Túnez (2010-2011), Libia (2011), Egipto (2012), Yemen (2012) y cambios en las políticas de gobierno de Jordania, Argelia, Omán, Irak, Marruecos y otros. 
Si bien, algunos sectores que se exagera el impacto que se da al papel que las redes sociales virtuales han tenido en los eventos citados, es innegable que papel importante han cumplido como vehículo para la distribución de ideas, comunicación de reclamos y de participación ciudadana.

Fueron reclamos del mundo real realizados en el mundo virtual que luego se convirtieron en reclamos reales en el mundo real al convocar a los ciudadano/usuarios/individuos a las manifestaciones. Esto puede considerarse como ejemplo de lo que Castell llama "virtualidad real".

\subsection{La Sociedad Red y la Cultura de la Virtualidad Real}

Un aspecto interesante de la sociedad red es lo que Castells llama de cultura de la "Virtualidad Real”. Ahora bien, el encuentro de estas dos palabras, en principio antagónicas, puede resultar incoherente.

La realidad es la existencia material, es lo que nos rodea y podemos tocar o sentir. O tal como define la Real Academia Española es lo "que tiene existencia verdadera y efectiva". Lo virtual, por su parte es, "tiene existencia aparente y no real". Otra acepción importante es la que dice que: "tiene virtud para producir un efecto, aunque no lo produce de presente"

En la época actual se habla mucho de la realidad virtual. Ésta es, según la Real Academia Española la "representación de escenas o imágenes de objetos, producida por un sistema informático, que da la sensación de su existencia real”. En otras palabras, en el espacio informático se producen hechos o situaciones que para nosotros son reales y tienen efecto sobre nuestra existencia verdadera, aunque no sean materiales.

En el concepto que Castells acuñó de la virtualidad real la situación se da a la inversa, se llevan hechos de la realidad al espacio cibernético se las incorpora a ese espacio y luego son devueltas al mundo material como virtuales. Es un intercambio constante de realidad y virtualidad. 
Explica Castells que nuestra realidad siempre ha sido virtual ya que la humanidad se maneja mediante un entorno simbólico y aquella se percibe "a través de símbolos que formulan la práctica con algún significado que se escapa de su estricta definición semántica" (Castells, 1996, p. 406)

Lo específico de esta etapa histórica es la virtualidad real:

Es un sistema en el que misma realidad (esto es la existencia material/simbólica de la gente) es capturada por completo, sumergida de lleno en un escenario de imágenes virtuales, en el mundo de hacer creer, en el que las apariencias no están solo en la pantalla a través de la cual se comunica la experiencia, sino que se convierten en la experiencia. (Castells, 1996, p. 407)

Así por ejemplo, las llamadas "redes sociales" en el ciberespacio son muchas veces un trasiego al mundo informático de las redes sociales que en la realidad material se tienen. Mantener contacto con la familia, los amigos, los ex compañeros de colegio o facultad y los colegas de trabajo es llevar a la pantalla de la computadora una experiencia que ya es compartida en la vida fuera de ella. Sin embargo, teniendo estas redes materiales por base, se forman otras en la "realidad informática", que en muchas ocasiones no saltan a la realidad material.

Así, hay usuarios de Facebook que poseen mil contactos, de los cuales con solo un promedio de 120 a 130 personas se mantiene una relación más estrecha vía web. Con los demás "amigos" apenas son contactos, que pocas veces salen de la realidad virtual a la realidad material. En este último caso se materializa la virtualidad y la relación aparente en el ciberespacio se hace real en el mundo de los sentidos. Eso es virtualidad real.

\subsection{La comunicación en la sociedad como poder del individuo - ciudadano: algunas conclusiones}

La participación política del individuo también se ve afectada, influenciada y propiciada por las tecnologías de la información la comunicación.

Así, con los medios masivos de comunicación se daba información de uno a muchos. Las TICs, con Internet a la cabeza, han favorecido que la información parta de muchos a muchos. 
Resulta difícil pretender el control de Internet. Cuando no imposible. Pero esto no es óbice para que los gobiernos no lo intenten de vez en vez disfrazados de políticas de protección a la privacidad individual, protección de propiedad intelectual o de ciertos grupos sociales como los niños o las mujeres.

Al respecto Castells menciona una sentencia interesante de la Suprema Corte de los Estados Unidos que sostiene que Internet es un caos, pero el ciudadano tiene "derecho constitucional al caos". Podemos decir esta visión interesante del derecho constitucional bien puede insertarse en uno de los aspectos de los derechos humanos de cuarta generación.

Ahora bien, ¿donde se inserta el poder del individuo como ciudadano dentro de este derecho al caos?

Tal como se ha mencionado al tratar de la teoría individualista de John Locke, el hombre considerado individualmente en su estado natural posee derechos y libertades que le son ilimitadas y para cuya organización solo él puede auto reglarse conforme a la ley natural. Tales derechos y libertades son iguales a la que poseen otros individuos (por lo que existe la horizontalidad en el estado natural). Pero esa regla individual puede entrar (y de hecho entra) en conflicto con las reglas de otros individuos. Para que sea posible la sociedad civil debe haber consentimiento. ¿Consentimiento para qué?

La función de la sociedad civil es garantizar mediante una ley que sea reflejo de la ley natural que los derechos y libertades de cada individuo sean respetados por los demás individuos.

Para manifestar ese consentimiento debe haber comunicación. Para Castells “(...) nuestras mentes viven inmersas en un entorno de comunicación de donde reciben las señales con las que se activan las emociones, se generan los sentimientos y se forman las decisiones." (Castells, M. 2012).

El medio de comunicar la voluntad individual en las sociedades democráticas modernas es mediante el voto, manifestado en elecciones periódicas. Es el instrumento propio de las democracias representativas, modelo básico de gobierno desde que la era moderna fue inaugurada con la Constitución de Virginia en 1776. 
Sin embargo, otros instrumentos de democracia directa como el referéndum, el plebiscito y el derecho de petición a las autoridades no fueron relegados de las constituciones modernas y conforman, junto con el voto universal, libre, directo, igual y secreto el aspecto descriptivo de las democracias.

Ahora bien, se hace necesario ampliar ese concepto descriptivo de democracia 214 para incluir otro elemento importante de este aspecto, sin el cual las herramientas mencionadas no sirven más que como puntos que chequear para los observadores internacionales. Tal elemento es la participación ciudadana.

La dinámica actual de las tecnologías de la información y de la comunicación ha rescatado y revalorizado la participación del ciudadano en toma de las decisiones políticas y han determinado un nuevo significado para la expresión "poder del pueblo".

(...) existe una relación básica entre comunicación poder (...) (que) se ha acentuado profundamente en lo que llamo la sociedad red, una sociedad en la que las redes de comunicación interactiva de base electrónica y trasmisión digital organizan el conjunto de las prácticas sociales del planeta en términos de la interacción de lo global y lo local. (Castell, 2012)

Cada cual se constituye en generador y receptor de información, que contribuye a potenciar el conocimiento sobre el tema específico que se trate. Esto permite una mayor predisposición del individuo de presentar propuestas y de aceptar o rechazar las que se presenten.

(...) estamos en un entorno eminentemente participativo. De hecho, la red se retroalimenta constantemente de las señales que emiten sus usuarios. Esta participación conduce inexorablemente a la interacción, es decir, a la relación con lo que hacen los demás (no hablamos de intensidad o grados de dicha relación, sino que participar significa mover información propia en relación con los otros y mover información de los otros en relación con la propia).

El resultado inescapable de ambos puntos es un crecimiento constante de la información y el conocimiento que circula por el sistema. (Alicia Silva Silva, 2008, p. 130)

Estas tecnologías de la comunicación han facilitado, además, que el individuo preste su consentimiento y así se convierta en miembro de la sociedad, tal como lo enunciado por Locke, las más de las veces se tratan de consentimiento tácito. Los "fans page" de Facebook, pueden ser utilizados como indicadores acerca de temas que son de interés para la sociedad. 
Como se ha visto en la primera parte de este trabajo, la actuación en redes facilitadas por la tecnología permite al ciudadano encontrar voluntades individuales similares a la suya, las que al unirse contribuyen a la transformación de la sociedad política. Al no ser el origen de la sociedad civil de un consenso unánime y menos aun no poseer unanimidad las decisiones adoptadas por la asamblea legisladora, las sociedades con intereses comunes que se forman, por su vez, entran en contacto con otras sociedades con intereses afines, formando "redes" de auxilio, que aunando esfuerzos buscan sumar para tener los intereses de las mismas atendidas.

El concepto de redes sociales no se excluye del pensamiento lockeano de la sociedad civil y de su origen mediante el consentimiento y el contrato, sino que viene a ser el complemento de esta sociedad civil que obliga a sus miembros perfectos a someterse a los dictados de la voluntad de la mayoría, pero que no por ello obvia que existen voluntades que no se encajan en ella. Y ya que cada individuo conserva su facultad originaria de buscar lo mejor para su preservación, manifiestan su voluntad en la búsqueda de ese bien.

Así, es innegable que la acción por medio de las redes sociales fomentadas por las tecnologías de información y comunicación han dado un nuevo aire a los derechos de asociación, reunión y manifestación y han permitido a los usuarios-ciudadanos percibir que tienen mucho más en común que la lista de contactos, generando un efecto "bola de nieve" a las reclamaciones vertidas en la red, que va en crescendo hasta que la indignación extrapola más allá de la pantalla del ordenador, por medio de la auto convocatoria, que hace al ciudadano dejar su casa y salir a las calles.

Son las “ciberturbas" como denominó David Ugarte en "El poder de las redes" (s.f.), que nos conducen a aquel modelo de libertad individual pregonado por Locke y Hobbes y que hacen de cada individuo arquitecto de su propio destino. ${ }^{2} \mathrm{Y}$ en esa arquitectura individual se contribuye a la vez a la arquitectura del país en general.

\section{Reflexiones desde la realidad paraguaya - Uso de Internet en Paraguay}

Desde el Censo de 2002, la Dirección General de Estadísticas, Encuestas y Censo (DGEEC) monitorea los datos de hogares con conexión a Internet. Así tenemos que para 
aquel censo, solo el 6,4\% de los hogares paraguayos poseía una computadora y 1,7 \% la poseían con conexión a Internet. (DGEEC, 2004, p. 30)

En menos de 10 años esos números han sufrido una variación positiva bastante significativa. En la Encuesta Permanente de Hogares (EPH) del año 2011, se observa que los hogares con computadoras conectadas a Internet llegan a 21,8\%. (DGEEC, 2012, p. 32). Este número es incluso muy superior al año de 2010, en que el EPH arroja el resultado de que solo el 13,8\% poseen computadoras conectadas a Internet. (DGEEC, 2011, p. 28) ¿A qué se debería esa diferencia tan expresiva en tan solo un año?

Con relación al tópico utilización de Internet por la población, independiente de poseer o no una computadora, la DGEEC incluye su análisis desde el EPH del año 2006. En el mismo se tiene que solo el $8 \%$ de la población del periodo mencionado usaba Internet. (DGEEC, 2007, p. 34). Ese número triplicó en el año 2011, llegando al 24\% de la población que manifiesta usar Internet, conforme a los datos del EPH del 2011. (DGEEC, 2012, p. 30). Se entiende por persona que ha utilizado Internet "a aquella que ha utilizado el servicio de Internet al menos dos veces dentro de los últimos 3 meses inmediatamente anteriores a la fecha de la entrevista" que genera el resultado de la encuesta. (DGEEC, 2011, p. 129)

Una de las causas para la mayor utilización de Internet puede hallarse en el aumento de la oferta del servicio de provisión y la disminución de los costos para el acceso el mismo, fruto de la competición entre las principales empresas de telefonía móvil que operan en el país. Actualmente, todas brindan servicios de Internet móvil (con auxilio de un módem para instalarlo en la computadora) a precios que varían desde guaraníes 59.000 (Vox) a guaraníes 60.000 (Personal, Tigo, Claro) ${ }^{3}$ mensuales, con capacidad de hasta un giga. A esto se suma la posibilidad de utilizar Internet desde los aparatos celulares y el servicio de provisión de Internet fijo que presta COPACO y otros proveedores.

Datos de la CONATEL, expresados en la Matriz de Indicadores de Desarrollo de Telecomunicaciones, de setiembre de 2012, muestran que hasta junio de 2012 había 6.617.655 suscripciones a telefonía móvil. (CONATEL, 2012, p. 1). Esto coincide con los datos del EPH 2011, que muestra que el 88,9\% de los hogares paraguayos cuentan con aparato de teléfono móvil. (DGEEC, 2012, p. 24) 
En cuanto a las suscripciones a Internet móvil, el mismo estudio de la CONATEL señala que hasta junio de 2012 el total de suscripciones alcanzaba 327.289. (CONATEL, 2012, p. 1). Un aspecto interesante del estudio indica que hasta diciembre de 2011, las suscripciones a Internet móvil de banda ancha con capacidad entre 0,512 kbps y 2 Mbps llegaban a 287.229. (CONATEL, 2012, p. 1). Luego, en enero de 2012, ese número disminuyó drásticamente a casi la mitad, 108.364 suscripciones. (CONATEL, 2012, p. 1). Sin embargo, la Internet móvil con capacidad entre 2 y 10 Mbps comenzó a ser utilizada, señalándose 190.043 suscripciones. (CONATEL, 2012, p. 1). A partir de ese momento ambas líneas de capacidad comienzan a ir en aumento:

\begin{tabular}{|c|c|c|c|c|c|c|c|}
\hline $\begin{array}{c}\text { Capacidad/ } \\
\text { Periodo }\end{array}$ & Enero/2012 & Febrero/2012 & Marzo/2012 & Abril/2012 & Mayo/2012 & Junio/2012 & \\
\hline $\begin{array}{c}\text { entre } 0,512 y \\
2 \mathrm{Mbps} \\
\end{array}$ & 108.364 & 11.099 & 114.093 & 117.124 & 102.335 & 123.396 & suscripciones \\
\hline $\begin{array}{c}\text { entre } 2 \text { y } 10 \\
\text { Mbps }\end{array}$ & 190.043 & 194.938 & 198.012 & 198.927 & 200.938 & 203.865 & suscripciones \\
\hline
\end{tabular}

Fuente: CONATEL, Setiembre de 2012, p. 1

Estos datos son coincidentes con una mayor oferta a un precio más accesible de la provisión de Internet en las líneas de capacidad indicadas.

Con relación a la provisión del servicio de Internet fijo, también tienen hasta junio de 2012, 129.907 suscripciones. Así, sumadas todas las suscripciones de Internet hasta mediados del 2012 se tiene 457.196 suscripciones a Internet en el país.

\begin{tabular}{|c|c|c|c|c|}
\hline $\begin{array}{c}\text { Capacidad/ } \\
\text { Periodo }\end{array}$ & Diciembre/2010 & Diciembre/2011 & Junio/2012 & \\
\hline Internet Móvil & 217.723 & 287.229 & 327.289 & suscripciones \\
\hline Internet Fijo & 105.731 & 118.966 & 129.907 & suscripciones \\
\hline $\begin{array}{c}\text { Total de } \\
\text { Suscripciones }\end{array}$ & 323.454 & 417.407 & 457.196 & suscripciones \\
\hline
\end{tabular}

Fuente: CONATEL, Setiembre de 2012, p.s. 1/2

Estos datos implican un aumento de 41,3\% del posible uso de Internet desde 2010 y de $9,53 \%$ desde 2011 hasta junio de 2012.

En cuanto a las razones que llevan al uso de Internet, el siguiente cuadro realizado en base a los datos de los EPH, desde 2006 hasta el 2011 y tomando en cuenta los cinco 
tópicos con mayores porcentajes, muestra la variación que ha tenido ese punto en los seis años desde que la DGEEC ha incluido el análisis del mismo. Así tenemos:

\begin{tabular}{|c|c|c|c|c|c|c|}
\hline Año/Motivos & 2006 & 2007 & 2008 & 2009 & 2010 & 2011 \\
\hline Obtener Información & $46,1 \%$ & $16,6 \%$ & $12,0 \%$ & $21,7 \%$ & $17,3 \%$ & $11,4 \%$ \\
\hline Comunicación & $17,5 \%$ & $27,2 \% 5$ & $32,7 \%$ & $47,9 \%$ & $16,2 \%$ & $53,5 \%$ \\
\hline $\begin{array}{c}\text { Educación y } \\
\text { Aprendizaje } \\
\text { (capacitación en 2011) }\end{array}$ & $17 \%$ & $40,3 \%$ & $38,1 \%$ & $25,4 \%$ & $44,2 \%$ & $23,5 \%$ \\
\hline Entretenimiento & $14,3 \%$ & $10,8 \%$ & $6,6 \%$ & & $\ldots \ldots \ldots \ldots$ & $4,4 \%$ \\
\hline Leer periódico o revista & $3,5 \%$ & $3,8 \%$ & $8,8 \%$ & $1,4 \%$ & $6,4 \%$ & $4,9 \%$ \\
\hline $\begin{array}{c}\text { Usar/descargar juegos } \\
\text { videos películas }\end{array}$ & & & & $2,2 \%$ & $10,7 \%$ & \\
\hline
\end{tabular}

Elaboración propia en base a los datos de los diferentes EPH.

Las razones de uso en general no han variado, pero si la intensidad de su preferencia por la población paraguaya. Así tenemos que el principal uso de obtener información, que en el 2006 motivaba al 46,1\% de la población, ocupa el tercer puesto de las razones de uso, conforme al EPH del año 2011. En cambio las razones de educación y aprendizaje y comunicación se alternan prácticamente en el primer y segundo lugares desde el año 2007.

\begin{tabular}{|c|c|c|c|c|c|}
\hline Año/posición & 1 & 2 & 3 & 4 & 5 \\
\hline 2006 & $\begin{array}{c}\text { Obtener } \\
\text { Información, } \\
46,1 \%\end{array}$ & $\begin{array}{c}\text { Comunicación, } \\
17,5 \%\end{array}$ & $\begin{array}{c}\text { Educación y } \\
\text { Aprendizaje, 17\% }\end{array}$ & $\begin{array}{c}\text { Entretenimiento, } \\
14,3 \%\end{array}$ & $\begin{array}{c}\text { Leer periódico o } \\
\text { revista, } 3,5 \%\end{array}$ \\
\hline 2007 & $\begin{array}{c}\text { Educación y } \\
\text { Aprendizaje, 40,3\% }\end{array}$ & $\begin{array}{c}\text { Comunicación, } \\
27,2 \% 5\end{array}$ & $\begin{array}{c}\text { Obtener } \\
\text { Información, } \\
16,6 \% \\
\end{array}$ & $\begin{array}{c}\text { Entretenimiento, } \\
10,8 \%\end{array}$ & $\begin{array}{l}\text { Leer periódico o } \\
\text { revista, } 3,8 \%\end{array}$ \\
\hline 2008 & $\begin{array}{c}\text { Educación y } \\
\text { Aprendizaje, } 38,1 \%\end{array}$ & $\begin{array}{c}\text { Comunicación, } \\
32,7 \%\end{array}$ & $\begin{array}{c}\text { Obtener } \\
\text { Información, } \\
12,0 \% \\
\end{array}$ & $\begin{array}{l}\text { Leer periódico o } \\
\text { revista, } 8,8 \%\end{array}$ & $\begin{array}{c}\text { Entretenimiento, } \\
6,6 \%\end{array}$ \\
\hline 2009 & $\begin{array}{c}\text { Comunicación, } \\
47,9 \%\end{array}$ & $\begin{array}{c}\text { Educación y } \\
\text { Aprendizaje, } \\
25,4 \%\end{array}$ & $\begin{array}{c}\text { Obtener } \\
\text { Información, } \\
21,7 \% \\
\end{array}$ & $\begin{array}{l}\text { Usar/descargar } \\
\text { juegos videos } \\
\text { películas, } 2,2 \%\end{array}$ & $\begin{array}{l}\text { Leer periódico o } \\
\text { revista, } 1,4 \%\end{array}$ \\
\hline 2010 & $\begin{array}{c}\text { Educación y } \\
\text { Aprendizaje, } 44,2 \%\end{array}$ & $\begin{array}{c}\text { Obtener } \\
\text { Información, } \\
17,3 \% \\
\end{array}$ & $\begin{array}{c}\text { Comunicación, } \\
16,2 \%\end{array}$ & $\begin{array}{c}\text { Usar/descargar } \\
\text { juegos videos } \\
\text { películas, } 10,7 \%\end{array}$ & $\begin{array}{l}\text { Leer periódico o } \\
\text { revista, } 6,4 \%\end{array}$ \\
\hline 2011 & $\begin{array}{c}\text { Comunicación, } \\
53,5 \%\end{array}$ & $\begin{array}{l}\text { Educación y } \\
\text { capacitación, } \\
23,5 \%\end{array}$ & $\begin{array}{c}\text { Obtener } \\
\text { Información, 11,4\% }\end{array}$ & $\begin{array}{l}\text { Leer periódico o } \\
\text { revista, } 4,9 \%\end{array}$ & $\begin{array}{c}\text { Entretenimiento, } \\
4,4 \%\end{array}$ \\
\hline
\end{tabular}

Elaboración propia en base a los datos de los diferentes EPH.

Estos datos confirman algunos estudios de mercado que muestran los usos de Internet para Latinoamérica, como el divulgado por el sitio Tendencias digitales que indican que entre los diez primeros usos dados Internet se encuentran por orden: correos (89\%), redes sociales $(84 \%)$, noticias $(80 \%)$, descargas $(75 \%)$, chats $(75 \%)$, ver videos $(72 \%)$, trabajar con información (69\%), estudiar información (65\%), publicar fotos (58\%) y producir información (53\%). (Tendencias digitales, 2011) 
El mismo estudio divulgado por Tendencias Digitales muestra que en Paraguay ocupa primer lugar el uso de Internet para información y socialización. (Tendencias digitales, 2011).

Ahora bien, este uso de información y socialización se hace por varios canales propios de la red. Buscadores, redes sociales y páginas webs de canales de comunicación son de acceso frecuente en esta situación. Conforme al sitio Alexa.com, que realiza una valoración de los sitios webs más visitados, los siguientes ocupan los primeros lugares de frecuencia de visitas en el Paraguay:

\begin{tabular}{|l|l|l|l|}
\hline $1^{\circ}$ & Facebook, facebook.com & $11^{\circ}$ & Twitter, twitter.com \\
\hline $2^{\mathrm{o}}$ & Google Paraguay, google.com.py & $12^{\circ}$ & UltimaHora.com, ultimahora.com) \\
\hline $3^{\mathrm{o}}$ & YouTube, youtube.com & $13^{\circ}$ & Yahoo!, yahoo.com \\
\hline $4^{\mathrm{o}}$ & Google, google.com & $14^{\circ}$ & delta-search.com, delta-search.com \\
\hline $5^{\mathrm{o}}$ & Amazon.com, amazon.com & $15^{\circ}$ & IMbooster official website, iminent.com \\
\hline $6^{\circ}$ & Windows Live, live.com & $16^{\circ}$ & Softonic, softonic.com \\
\hline $7^{\circ}$ & ABC Digital, abc.com.py & $17^{\circ}$ & HOY, hoy.com.py \\
\hline $8^{\circ}$ & Blogspot.com, blogspot.com & $18^{\circ}$ & D10 - La magia del deporte, d10.com.py \\
\hline $9^{\circ}$ & Paraguay.com, paraguay.com & $19^{\circ}$ & Google España, google.es \\
\hline $10^{\circ}$ & Wikipedia, wikipedia.org & $20^{\circ}$ & Tigo.com.py, tigo.com.py \\
\hline
\end{tabular}

Fuente: Alexa.com, 2013.

Así, en el ranking indicado es posible observar que los datos proporcionados por los distintos estudios de la EPH citados y el estudio mencionado de Tendencias Digitales se confirman. Facebook es una red social, cuyos usos de comunicación y socialización están siendo complementados con los de obtención y difusión de información.

Google Paraguay es buscador, por lo que uso inmediato es obtener información. La página de Windows live se halla vinculada al servicio de correo electrónico popular que administra, sea el hotmail o el outlook, más reciente.

La motivación de educación y aprendizaje puede estar asociada al sitio web de la enciclopedia virtual de Wikipedia. 
Entre las páginas nacionales mejor posicionadas se halla la de ABC Digital, página de prensa, la versión electrónica del periódico impreso, con los complementos propios de la tecnología Web 2.0. Otras páginas de noticias que figuran en el ranking (Paraguay.com, $9^{\circ}$; ÚltimaHora.com, $12^{\circ}$ y $\mathrm{HOY}, 1^{\circ}$ ) confirman la motivación indicada más arriba de obtener información y leer periódico, revistas.

Los datos señalados permiten verificar, también en Paraguay, la tendencia a la progresiva penetración de Internet en varios ámbitos de la vida social del país y su creciente implementación.

\subsection{El debate público nacional en las redes sociales}

Se ha mencionado más arriba acerca de la mayor presencia de Internet en los hogares paraguayos. En el EPH del año 2006 se indicaba que 51,4\% que utilizó Internet lo hizo desde lugares públicos, por ej. un cyber café. Solo el $14,1 \%$ lo hizo en su hogar. (DGEEC, 2007, p. 35)

En el EPH del año 2011 la balanza se inclina a favor del acceso a Internet en el hogar, con 66,7\% de la población que manifiesta haber utilizado desde la residencia propia. Solo un 9,8\% dicen haberlo hecho desde sitios públicos. También en este EPH se menciona que el 6,2\% lo hace desde celulares. (DGEEC, 2012, p. 31)

El uso de Internet desde el hogar permite un contacto más frecuente y atento al contenido divulgado en la red. Esto, podría llevar, también, a una mayor reflexión sobre los asuntos puestos en tela de juicio en determinado momento.

Los datos que se han mencionado con relación al aumento de la penetración de Internet en el Paraguay en los últimos seis años y, en particular, al salto significativo que experimentó entre el año de 2010 y el primer semestre de 2012, con el aumento de las suscripciones a la banda ancha, conforme a los datos divulgados por la CONATEL, permiten entender ciertos hechos que ha tenido lugar en el año de 2012 y que tienen al uso de las redes sociales virtuales como una de las protagonistas. 
No se hallaron estudios académicos o sociológicos sobre el uso de Internet o redes sociales en el país, pero si se encontraron infografías disponibles en diferentes sitios sobre tales usos destinados a las empresas que visen utilizar las TICs para explorar nuevos mercados y como estrategias de marketing.

Así, un estudio divulgado por la organización Social Media Day Asunción, en base a datos recabados por el Diario Última Hora en el año de 2012, muestra que 53\% de los usuarios de redes sociales las utiliza más de tres horas al días, con diferentes propósitos. Los principales son: noticias (48\%), contactos (33\%), trabajo (14\%), juegos (2\%) y otras actividades $(1 \%)$.

Conforme al estudio citado, la red social más utilizada en nuestro país es Facebook, con $65 \%$ de la preferencia de los encuestados, seguidas de Twitter, con $29 \%$ y YouTube con 4\%. Esto coincide con los datos mencionados del sitio Alexa.com, que muestra que el primer sitio más visitado en Paraguay es Facebook. (Última Hora y otros, 2012)

Con base en los datos mencionados, se puede considerar a Facebook la red social por excelencia en nuestro país, por lo que no es de extrañar que delante de los masivos protestos que han tenido lugar entre los meses de mayo y julio del año 2012 se atribuya a la convocatoria en esta red su génesis.

Entre las principales características de la tecnología de la Web 2.0, mencionadas por Tim O’Reilly (2006) está que el usuario de la misma puede controlar los datos que se ingresan, lo que permite una participación más activa en el sitio visitado y una mayor interacción entre los usuarios.

Esto facilita el debate, sin que sea necesario salir propiamente de enfrente de la computadora. El usuario al obtener al estar conectado tanto tiempo obtiene mayor información, se entera más rápidamente de los hechos y la emisión de una opinión es más efectiva, pudiendo hacerse en forma anónima, incluso.

La participación en el debate público sobre los temas de interés de la sociedad en ciertos momentos se ve facilitada por esta herramienta. 


\subsection{Los hechos de mayo y junio de 2012}

El 24 de mayo de 2012 la Cámara de Diputados aprueba una presupuesta de cincuenta millones de dólares para la Justicia Electoral, que sería destinado a la contratación de funcionarios. El asunto que genera controversia es que los funcionarios que serían contratados son indicados por los partidos políticos, por lo que empieza a considerarse el presupuesto aprobado como una ampliación presupuestaria para esos partidos políticos que les permita la contratación de operadores políticos. Esta ampliación había sido aprobada en marzo y fue vetada por el entonces presidente Fernando Lugo.

Con consignas como "fuera dipuchorros" (como empiezan a ser denominados los legisladores que aprobaron el presupuesto) empiezan a reunirse frente al Congreso Nacional. Las estimaciones hablan de alrededor de dos mil (ABC Digital, 2012) a cinco mil (Última Hora.com, 2012) personas que se habían reunido en la oportunidad para manifestarse. El medio de convocación: las redes sociales.

La presión de cuatro días de movilizaciones trajo como resultado la decisión de la Cámara de Senadores de aprobar por mayoría el veto presidencial la ampliación del presupuesto.

La posibilidad de influir en las decisiones de los parlamentarios generó una suerte de síndrome de "superman" en los movilizados que, tras la conquista citada, fueron en pos nuevos retos.

Casi inmediatamente al tratamiento del presupuesto de la Justicia Electoral, y aprovechando el clima favorable a las presiones de la ciudadanía, se convocó a sesión extraordinaria de la Cámara de Senadores para tratar la Ley que promovía el desbloqueo de las listas de los partidos políticos que contenían las candidaturas al Parlamento.

La petición esta vez recaía sobre lo que llamaban el desbloqueo real de las listas. Se proponía eliminar el sistema D'Hondt para ordenar las listas plurinominales y se pretendía implantar un sistema en el cual la lista de candidatos se ordenara de acuerdo al número de votos que recibieran estos, otorgando al elector la facultad de votar directamente por el candidato de su preferencia dentro de la lista. 
El resultado no fue el esperado, a pesar de los vaticinios favorables a las movilizaciones ciudadanas. Por 29 votos contra 15 se rechazó el proyecto de desbloqueo de las listas cerradas, lo que desencadenó la furia de los manifestantes apostados frente al Congreso, muchos de los cuales fueron protagonistas de hechos vandálicos, contra sedes de partidos políticos e instituciones del Estado, como el Congreso.

Ambas movilizaciones en un espacio muy corto de tiempo, con resultados tan opuestos se consideran frutos de convocatorias realizadas mediante el uso de redes sociales, en especial Facebook y Twitter.

\subsection{El "After Office Revolucionario" y asociaciones}

“After office" es literalmente después de la oficina. Se refiere en general a las salidas con los compañeros de trabajo luego de terminar la jornada laboral con fines de ocio y descanso. Sin embargo, la convocatoria del momento no era para ocio, y si para manifestación.

Como "After office revolucionario" queda conocida la serie de manifestaciones que tuvieron sus causales en los hechos más arriba mencionados. También se las denominaron Indignados - Paraguay, en coincidencia con las manifestaciones ocurridas en España en el 2011 y “OccuPY Asunción”, que es menos frecuente.

Con todas esas denominaciones es posible hallar diferentes perfiles, sea como personas, grupos o comunidad en Facebook. También en Twitter se hallan presentes.

Además de las denominaciones mencionadas, muchos otros movimientos surgieron en Facebook que promocionaron la participación en las manifestaciones en los meses de mayo y junio del 2012. Algunos de ellos ya existían antes de los hechos mencionados, tales como la Asociación Fuera Listas Sábanas (desde Enero de 2011 en Facebook) y Basta ya, Seguridad en Paraguay (desde Agosto de 2011). Otros como, el propio After Office Revolucionario y Che Kueraima - Indignados Paraguay, tuvieron su perfiles creados a partir de los hechos de mayo y junio de 2012. 
El After Office Revolucionario tuvo varias versiones en el interior del país, y para cada versión se habilitó un perfil en Facebook, como para las movilizaciones en Encarnación y Villarrica.

Por otro lado, se encontraron tantos movimientos afines a partir de las convocaciones en las redes sociales mencionadas que se creó una Coordinadora de Grupos Ciudadanos en las Redes Sociales del Paraguay, que agrupaba a varios grupos, como: Basta Ya, Debatamos Paraguay, After Office Revolucionario y La Gran Marcha.

Un movimiento que surgió luego del juicio político de Fernando Lugo en junio de 2012 y en virtud de lo que considera la injerencia de los países de la región en asuntos internos del país, es Paraguay es Soberano. Posee dos cuentas en Facebook, Paraguay es Soberano con 40.986 miembros y Paraguay Soberano con 23.951 miembros. Es uno de los grupos, si no el grupo, con más seguidores dentro de las redes sociales que han surgido en virtud de los hechos de mayo y junio de 2012.

Muchos de los grupos que se citan, además de sus respectivos perfiles en las redes sociales mencionadas, hacen uso de otras herramientas de la tecnología 2.0 como blogs y páginas webs propias. Tal es el caso de Paraguay Es Soberano y Debatamos Paraguay.

El caso del movimiento After Office Revolucionario es emblemático, porque además se ha convertido en movimiento político, lanzando la candidatura del fundador del movimiento Maximiliano Urbieta como Diputado, en las elecciones de abril 2013. Si bien no logró ocupar un escaño en la Cámara baja, su movimiento, Despertar Ciudadano, logró obtener 9.661 votos, con una propuesta bastante interesante de voto electrónico, Yovoto.com, que rescata la idea del mandato directo e imperativo del legislador.

Las actividades de estos grupos no terminaron con el fin de las manifestaciones. Sus perfiles siguen activos y es posible observar que aun reciben nuevos "amigos" o miembros.

Con los datos más arriba indicados y con el relato de los hechos realizados se puede sugerir que el mayor acceso de la población a Internet y otras TICs trajeron como consecuencia una mayor participación de los usuarios en los temas propios de la agenda 
pública nacional, en especial por medio de las redes sociales, particularmente el Facebook. Esto porque se han ampliado los canales de comunicación directa entre cada usuario, que sumando los descontentos individuales generan el de la mayoría.

Esto, no obstante, no explica la razón que lleva al usuario a abandonar su computadora e integrarse a la manifestación. Se puede intuir cierto poder de sugestión y presión de los demás usuarios de las redes sociales. No obstante, también se debe presente otros factores no mencionados en este trabajo.

Finalmente, se atribuye toda suerte de males y beneficios a las redes sociales, pero lo que no se debe olvidar es que se trata de una herramienta y como tal su bondad o maldad dependerá de la mano que la use.

\section{Conclusiones Articuladas}

Se pudo ver en el transcurrir de ese artículo, la importancia de las redes sociales en el contexto del actual mundo globalizado, observando como el concepto de libertad, y en especial en del ejercicio de la libertad de expresión ha alcanzado su auge desde la utilización masiva de este medio de comunicación, que se ha instaurado de tal forma, y con tal arrastre que ha propiciado transformaciones sociales en todo el planeta.

Pudimos contextualizar como este fenómeno ingresó a la comunidad paraguaya, y ha influenciado las decisiones políticas en los últimos tiempos, en especial el caso analizado lo ocurrido en 2012, que consideramos fue la primera demostración del poder de las redes sociales dentro de la sociedad civil de Paraguay.

Este trabajo no pretende colocar un punto final al debate de la utilización de las redes sociales, al contrario se propone funcionar como un punto de partida a la aparición de otros trabajos de investigación dentro de la esfera académica, en la intención de tejer nuevos debates, fomentar la aparición de otras opiniones, en especial dentro de la República del Paraguay.

Una situación que reconocemos es que, este superorganismo formado por todos los seres humanos del planeta, que se encuentran conectados mucho más profundamente de lo 
que creíamos hasta ahora, aun traerá mucha discusión, y por ende transformaciones dentro de las estructuras sociales, y corresponde que acompañemos su proceso de evolución, para de esta forma entender cómo piensa y actúa la sociedad actual.

\section{Referencias}

ABC DIGITAL, (2012), Ciudadanos celebran decisión. Recuperado el: 09/06/2013. Disponible en http://www.abc.com.py/nacionales/ciudadanos-celebran-decision-4077...

ALEXA.COM, (2013), Top sites in Paraguay. Recuperado el 09/06/2013. Disponible en: http://www.alexa.com/topsites/countries/PY

BANCO MUNDIAL, (2013), Usuarios de Internet (por cada 100 personas. Datos disponibles en http://datos.bancomundial.org/tema/infraestructura\#wbboxes-source-IT-NETUSER-P2.

CANO RADIL, B. (2009), Teoría política. Historia de las ideas, ideología, poder, Estado y gobierno. Obstáculos para el desarrollo del Paraguay. Tomos I y II. Asunción: Ediciones Universidad del Pacífico.

CARDOZO CABAS, G. G., (2009), Historia del concepto de red Social. Recuperado el 06/12/2011. Disponible en:

http://api.ning.com/files/XTj6PLCPPuFqdfb7UgUqoC3MJP2Gp8uETdvZtgGysgOtikjOSDtmFBx*D5*s9HLJlx rxDDys-Q3WRdjAwQBay*fSCWgNomHy/Historiadelconceptoderedsocial.pdf

CASTELlS, M. (2006), A sociedade em Rede: do Conhecimento á Política. Recuperado el: 30/11/2012. Disponible en:

www.cies.iscte.pt/linhas/linha2/sociedade_rede/zip/Sociedade_em_Rede_CC.zip. Págs. 17 al 30.

Editorial.

(2009), Comunicación y Poder, (Hernández, María, trad.) Madrid: Alianza

(2001), Internet, libertad y sociedad: una perspectiva analítica.

Recuperado el 10/11/2012. Disponible en:

http://www.uoc.edu/web/esp/launiversidad/inaugural01/intro_conc.html\#

(2001), Internet y sociedad. Recuperado el 10/11/2012. Disponible en:

http://tecnologiaedu.us.es/nweb/htm/pdf/106.pdf

(1996), La sociedad red. La era de la Información: Economía, Sociedad y

Cultura. (Martínez Gimeno, Carmen, trad.) Madrid: Alianza Editorial.

CONATEL (2012), Matriz de Indicadores de Desarrollo de Telecomunicaciones.

Recuperado el 05/06/2013. Disponible en:

http://www.conatel.gov.py/documentos/Matriz\%20de\%20Indicadores\%20de\%20Desarrollo\% 20completo\%20a\%2006_2012.pdf 
DAROS, W.R. (s.f.), El derecho a ejercer la libertad según John Locke. Recuperado el: 19/02/2013. Disponible en: http://williamdaros.files.wordpress.com/2009/08/el-derecho-de-elegirsegc3ban-j-locke.pdf

Dirección General de Estadísticas, Encuestas y Censo, (2004), Paraguay, Resultados

Finales. Censo Nacional de Población y Viviendas. Año 2002 - Total País. Recuperado el: 09/06/2013. Disponible en:

http://www.dgeec.gov.py/Publicaciones/Biblioteca/Web\%20Paraguay\%20Total\%20Pais/1\%2 0Presentacion\%20Total.pdf

Dirección General de Estadísticas, Encuestas y Censo, (2005), Principales Resultados del EPH 2004. Encuesta Permanente de Hogares. Recuperado el: 09/06/2013. Disponible en: http://www.dgeec.gov.py/Publicaciones/Biblioteca/EPH2004/00-Presentacion.pdf

Dirección General de Estadísticas, Encuestas y Censo, (2006), Principales Resultados del EPH 2005. Encuesta Permanente de Hogares. Recuperado el: 09/06/2013. Disponible en:http://www.dgeec.gov.py/Publicaciones/Biblioteca/PRINCIPALES\%20RESULTADOS\% 20POR\%20DEPARTAMENTO\%20EPH2005/Primera\%20parte\%20EPH\%20por\%20Depart amentos\%202005.pdf

Dirección General de Estadísticas, Encuestas y Censo, (2007), Principales Resultados del EPH 2006. Encuesta Permanente de Hogares. Recuperado el: 09/06/2013. Disponible en:http://www.dgeec.gov.py/Publicaciones/Biblioteca/EPH2006_PRINCIPALES\%20RESUL TADOS\%20POR\%20DPTO/01Presentacion\%20EPH\%202006.pdf

Dirección General de Estadísticas, Encuestas y Censo, (2008), Principales Resultados del EPH 2007. Encuesta Permanente de Hogares. Recuperado el: 09/06/2013. Disponible en:http://www.dgeec.gov.py/Publicaciones/Biblioteca/EPH2007_PRINCIPALES\%20RESUL TADOS\%20POR\%20DPTO/01\%20PRESENTACION\%20EPH\%202007.pdf

Dirección General de Estadísticas, Encuestas y Censo, (2009), Principales Resultados del EPH 2008. Encuesta Permanente de Hogares. Recuperado el: 09/06/2013. Disponible en:http://www.dgeec.gov.py/Publicaciones/Biblioteca/EPH2008_PRINCIPALES\%20RESUL TADOS\%20POR\%20DPTO/Presentacion.pdf

Dirección General de Estadísticas, Encuestas y Censo, (2010), Principales Resultados del EPH 2009. Encuesta Permanente de Hogares. Recuperado el: 09/06/2013. Disponible en:http://www.dgeec.gov.py/Publicaciones/Biblioteca/EPH2009_PRINCIPALES\%20RESUL TADOS\%20POR\%20DPTO/INDICE_EPH2009.pdf

Dirección General de Estadísticas, Encuestas y Censo, (2011), Principales Resultados del EPH 2010. Encuesta Permanente de Hogares. Recuperado el: 09/06/2013. Disponible en:http://www.dgeec.gov.py/Publicaciones/Biblioteca/principales\%20resultados\%20eph\%202 010/1.INDICE.pdf

Dirección General de Estadísticas, Encuestas y Censo, (2012), Principales Resultados del EPH 2011. Encuesta Permanente de Hogares. Recuperado el: 09/06/2013. Disponible en:http://www.dgeec.gov.py/Publicaciones/Biblioteca/EPH2011/eph2011/1.\%20indice.pdf 
GODOY ARCAYA, O. (2004), Revista de Ciencia Política, Libertad y consentimiento en el pensamiento político de John Locke. 25 (2). Versión electrónica. Recuperado el: 19/02/2013. Disponible en: http://www.scielo.cl/pdf/revcipol/v24n2/art09.pdf

IBARRA, P. (2000), ¿Qué son los movimientos sociales? Recuperado el 05/12/2011. Disponible en: http://ctinobar.webs.ull.es/1docencia/Movimientos/PEDRO.pdf

O'REILLY, T, (2006), Qué es Web 2.0. Patrones del diseño y modelos del negocio para la siguiente generación del software. Tribuna. Recuperado el 09/06/2013. Disponible en: http://sociedadinformacion.fundacion.telefonica.com/url-direct/pdfgenerator?tipoContenido $=$ articulo\&idContenido $=2009100116300061$

\section{LOCKE, J. (s.f.) Segundo Tratado sobre el Derecho Civil.}

MONTÚFAR, F. CH. (coord.. gral.) (2010), Ciberactivismo de movimientos políticos en Ecuador. CIESPAL. Recuperado el 01/12/2012. Disponible en: http://www.fesecuador.org/media/pdf/FES_ILDIS-informe\%20final\%20Ciberpolitica.pdf

SERRANO SANTOYO, A. y MARTÍNEZ MARTÍNEZ, W. (2003), La brecha digital: mitos y realidades. Baja Californi: Editorial Universitaria de la Universidad de Baja California.

SCHERER - WARREN, I. (2006), Revista Sociedade e Estado. Das mobilizações ás redes de movimentos sociais. 21 (1). Págs. 109-130. Versión electrónica. Recuperado el:

05/11/2012. Disponible en: http://www.scielo.br/scielo.php?script=sci_arttext\&pid=S010269922006000100007

SCHERER - WARREN, I. (2005), Revista Nueva Sociedad, Redes sociales y de movimientos en la sociedad de la información. 196. Recuperado el: 05/12/2012. Disponible en: http://www.nuso.org/upload/articulos/3250_1.pdf

SILVA SILVA, A., (2008), El sujeto y la relación virtual. Recuperado el 10/11/2012. Disponible en: http://dialnet.unirioja.es/servlet/articulo?codigo=3986887

TENDENCIAS DigITALES, (2012), Hábitos del Uso de Internet en América Latina. Recuperado el 09/06/2013. Disponible en:

http://www.tendenciasdigitales.com/1461/infografia-usos-de-internet-en-latinoamerica-2012/

(2011), Infografía: los latinoamericanos en Internet. Recuperado el

09/06/2013. Disponible en: http://www.tendenciasdigitales.com/1340/infografia-loslatinoamericanos-en-internet/

UGARTE, D. (s.f.), El poder de las redes. Manual ilustrado para ciberactivistas.

Recuperado el 05/12/2011. Disponible en http://chuerta.com/libros/El_Poder_De_Las_Redes.pdf

UNESCO, (2005), Hacia las sociedades del conocimiento. Mayenne: Jouve

ÚTLIMAHORA.COM, (2012), Las imágenes del repudio ciudadano a los legisladores. Recuperado el: 09/06/2013. Disponible en:

http://www.ultimahora.com/home/imprimir_nota.php?idNota=531417 


\title{
ÚTLIMA HORA, SOCIAL MEDIA DAY - PARAGUAY Y OTROS, 2012), Encuestas redes sociales Paraguay. Recuperado el: 09/06/2013. Disponible en:
} http://www.dementesx.com/redes-sociales-en-paraguay-infografia/

\author{
VÁRNAGY, T, (s.f.), El pensamiento político de John Locke y el surgimiento del \\ Liberalismo. Recuperado el 19/02/2013.Diponible \\ en:http://biblioteca.clacso.edu.ar/ar/libros/moderna/cap2.pdf
}

\footnotetext{
11 "El hecho de que nos refiramos a sociedades, en plural, no se debe al azar, sino a la intención de rechazar la unicidad de un modelo "listo para su uso" que no tenga suficientemente en cuenta la diversidad cultural y linguística, único elemento que nos permite a todos reconocernos en los cambios que se están produciendo actualmente. Hay siempre diferentes formas de conocimiento y cultura que intervienen en la edificación de las sociedades, comprendidas aquellas muy influidas por el progreso científico y técnico moderno. No se puede admitir que la revolución de las tecnologías de la información y la comunicación nos conduzca -en virtud de un determinismo tecnológico estrecho y fatalista- a prever una forma única de sociedad posible". (UNESCO, 2005, p. 17)

${ }^{2} \mathrm{Al}$ respecto resulta interesante profundizar en el siguiente pensamiento de Ugarte: "Lo que define a una red distribuida es, como dicen Alexander Bard y Jan Söderqvist, que "todo actor individual decide sobre sí mismo, pero carece de la capacidad y de la oportunidad para decidir sobre cualquiera de los demás actores." En este sentido, toda red distribuida es una red de iguales, aunque haya nodos más conectados que otros. Pero lo importante es que, en un sistema de este tipo, la toma de decisiones no es binaria. No es «sí» o «no». Es «en mayor o menor medida». Alguien propone y se suma quien quiere. La dimensión de la acción dependerá de las simpatías y grado de acuerdo que suscite la propuesta. Este sistema se llama pluriarquía y, según los mismos autores, hace imposible mantener la noción fundamental de democracia, donde la mayoría decide sobre la minoría cuando se producen diferencias de opinión".

${ }^{3}$ Datos disponibles en las páginas webs de las respectivas empresas: Tigo: www.tigo.com.py. Personal: www.personal.com.py. Claro: www.claro.com.py. Vox: www.vox.com.py
} 